\title{
Stem cell therapy for the treatment of early stage avascular necrosis of the femoral head: a systematic review
}

\author{
Rick L Lau', Anthony V Perruccio², Heather MK Evans², Safiyyah R Mahomed², Nizar N Mahomed² \\ and Rajiv Gandhi ${ }^{2^{*}}$
}

\begin{abstract}
Background: Avascular necrosis (AVN) of the femoral head (FH) is believed to be caused by a multitude of etiologic factors and is associated with significant morbidity in younger populations. Eventually, the disease progresses and results in FH collapse. Thus, a focus on early disease management aimed at joint preservation by preventing or delaying progression is key. The use of stem cells (SC) for the treatment of AVN of the FH has been proposed. We undertook a systematic review of the medical literature examining the use of SC for the treatment of early stage (precollapse) AVN of the FH, in both pre-clinical and clinical studies.

Methods: Data collected included: Pre-clinical studies - model of AVN, variety and dosage of SC, histologic and imaging analyses. Clinical studies - study design, classification and etiology of AVN, SC dosage and treatment protocol, incidence of disease progression, patient reported outcomes, volume of necrotic lesion and hip survivorship.

Results: In pre-clinical studies, the use of SC uniformly demonstrated improvements in osteogenesis and angiogenesis, yet source of implanted SC was variable. In clinical studies, groups treated with SC showed significant improvements in patient reported outcomes; however hip survivorship was not affected. Discrepancies regarding dose of SC, AVN etiology and disease severity were present.
\end{abstract}

Conclusions: Routine use of this treatment method will first require further research into dose and quality optimization as well as confirmed improvements in hip survivorship.

Keywords: Avascular necrosis, Femoral head, Stem cells, Treatment, Precollapse

\section{Background}

Avascular necrosis (AVN) of the femoral head (FH) is a debilitating and painful disease with multiple etiologic risk factors [1-4]. These include, but are not limited to, corticosteroid use [1,3-6], alcohol abuse [1-4], previous trauma [1,3], hemoglobinopathy [7], Gaucher's disease and coagulopathies [8]. The onset of AVN may also be idiopathic [7]. AVN of the FH most commonly affects younger or middle aged adults $[2,9,10]$. Disease progression commonly leads to collapse of the affected $\mathrm{FH}$ and ultimately, development of osteoarthritis $[1,3,4,7,11,12]$. Outcomes of THA for these younger and more active

\footnotetext{
* Correspondence: rajiv.gandhi@uhn.ca

${ }^{2}$ Division of Orthopaedic Surgery, Toronto Western Hospital, 399 Bathurst Street EW 1-427, Toronto, Ontario M5T 258, Canada

Full list of author information is available at the end of the article
}

patients have been poor, primarily due to the limited lifetime and durability of total hip arthroplasty (THA) $[6,10,11]$. As a result, there has been an increased focus on early-interventions for AVN, aimed at preservation of the native articulation $[6,12]$. Core decompression (CD) is currently the most widely accepted treatment for earlystage AVN of the FH; however, due to limited efficacy, its use has been debated [12]. The development of safe, costeffective, and potentially minimally invasive joint preserving treatments for early stage (precollapse) AVN merits further investigation.

Several studies, both clinical and pre-clinical, have demonstrated the efficacy of stem cells (SC) for the treatment of AVN of the FH [1,3,11,13-15]. SC can be obtained from a variety of sources, including autologous bone marrow $[2,4,10,11,16,17]$, adipose tissue [10] and dental-pulp [4]. 
SC have been shown to promote bone formation $[4,6,11,12]$ and neovascularization $[6,11]$ in vitro. Additionally, patients treated with SC in conjunction with $\mathrm{CD}$ demonstrated significant improvements in Harris Hip Scores (HHS) [15] as well as decreased hip pain and symptoms compared to those treated with $\mathrm{CD}$ alone [2]. Yan et al. documented that stem cells implanted into the necrotic FH not only survive, but thrive and proliferate [15]. Although the pathogenesis of AVN is unclear [17] many hypothesize that SC work to improve early stage AVN potentially as a function of their critical role in the regulation and improvement of osteogenesis and angiogenesis [11,12]. Furthermore, it is thought that mesenchymal SC implanted into the necrotic FH may differentiate into osteoblasts or vascular endothelial cells, thereby promoting bone repair and regeneration [12]. Despite encouraging results in preclinical (basic science) and clinical studies, improvements in hip survivorship or time to THA has not been uniformly reported and remains controversial $[2,8,14]$.

The purpose of our study was to perform a systematic review of the current medical literature on the treatment of early stage AVN of the $\mathrm{FH}$ using SC implanted via $\mathrm{CD}$. We examined both preclinical studies and clinical studies. We reported bone healing outcomes (histologic and imaging outcomes) from preclinical papers and all examined outcomes from available clinical papers.

\section{Methods}

\section{Eligibility criteria}

Manuscripts were deemed eligible for our review if they evaluated treatment of early stage AVN of the FH with $\mathrm{SC}$ implanted via $\mathrm{CD}$. We defined early stage AVN as precollapse of the $\mathrm{FH}$. Both clinical and preclinical manuscripts were selected. For clinical trials, we included studies on patients age $>18$. All types of clinical studies were eligible for inclusion to this review. Studies of all languages were eligible for inclusion to this review. For studies reporting on the same group of patients at multiple follow up periods, the most recent publication was used in this review. For preclinical studies, manuscripts were eligible if they examined bone healing either histologically, or by imaging techniques. If studies examined other treatments such as vascularized fibular grafting or bone morphogenic proteins, they were excluded unless the data on SC and $\mathrm{CD}$ were presented separately from the other treatments, to allow us to examine the effect of SC specifically.

\section{Study identification}

A systematic, computerized search for potential manuscripts was performed by three independent reviewers (HE, SM, RL). Pubmed (-July 2012), Ovid Medline (-July 2012) and EMBASE (-July 2012) databases were used to identify studies. Key words used for the search were: AVN or avascular necrosis or osteonecrosis AND stem cells; AVN or avascular necrosis or osteonecrosis AND autologous bone marrow. Abstracts were retrieved for all manuscripts considered relevant by title. Abstracts were independently reviewed and any disagreements were resolved by discussion. Full length articles of relevant abstracts were reviewed for inclusion. Bibliographies of the full length articles were also searched for other potential studies and full length articles were retrieved.

Outcomes data were extracted by two reviewers (HE, RL) using prearranged summary tables. Data extraction for preclinical studies included study design, animal model, type of SC used, sample size, and outcomes measured. For the clinical studies, study type, sample size, potential biases, AVN classification, AVN etiology, SC dose and cell type, and outcomes measured were recorded.

\section{Results}

\section{Study selection}

We identified 215 abstracts using our electronic search. Thirty-four met the initial screening inclusion criteria and the full-length articles were retrieved and reviewed. Following the full-length reviews, 16 studies (11 preclinical, 5 clinical) met our inclusion criteria and were retained for this review. Eighteen studies were excluded: 3 were review articles [18-20], one was a surgical technique article [21], 3 articles were early/pilot results which were subsequently included in future articles [7,16,22], 6 articles examined SC treatment in conjunction with therapies other than CD (i.e. vascularized fibula) [23-28], two articles used SC transplanted intravenously instead of by CD [13,29], 1 article examined prevention of AVN not treatment [5], and two articles included patients with post collapse AVN of the FH [1,15] (Figure 1).

\section{Preclinical study characteristics Study design}

All preclinical studies utilized an animal model (8 rabbit [6,10,17,30-34], 2 dog [11,12] and 1 sheep model [4]). AVN was induced using methylprednisolone injection in 6 of the 11 studies [6,10,30-32,34]. One model utilized liquid nitrogen to create AVN of the FH [17]. Three studies utilized a femoral neck osteotomy to induce AVN $[11,12,33]$. One study induced AVN by instillation of ethanol to the $\mathrm{FH}$ via $\mathrm{CD}[4]$.

\section{Stem cell treatment}

The type of SC implanted were variable yet may be classified into three groups: 1) bone marrow derived stem cells - concentrated, un-cultured bone marrow mononuclear cells (BMMNC), fresh (1 study) [6] or cryopreserved (1 study) [32], and mesenchymal stem cells obtained post BMMNC culture (4 studies) [11,12,30,33]; 2 ) adipose derived stem cells (2 studies) [10,34]; 3 ) other - 


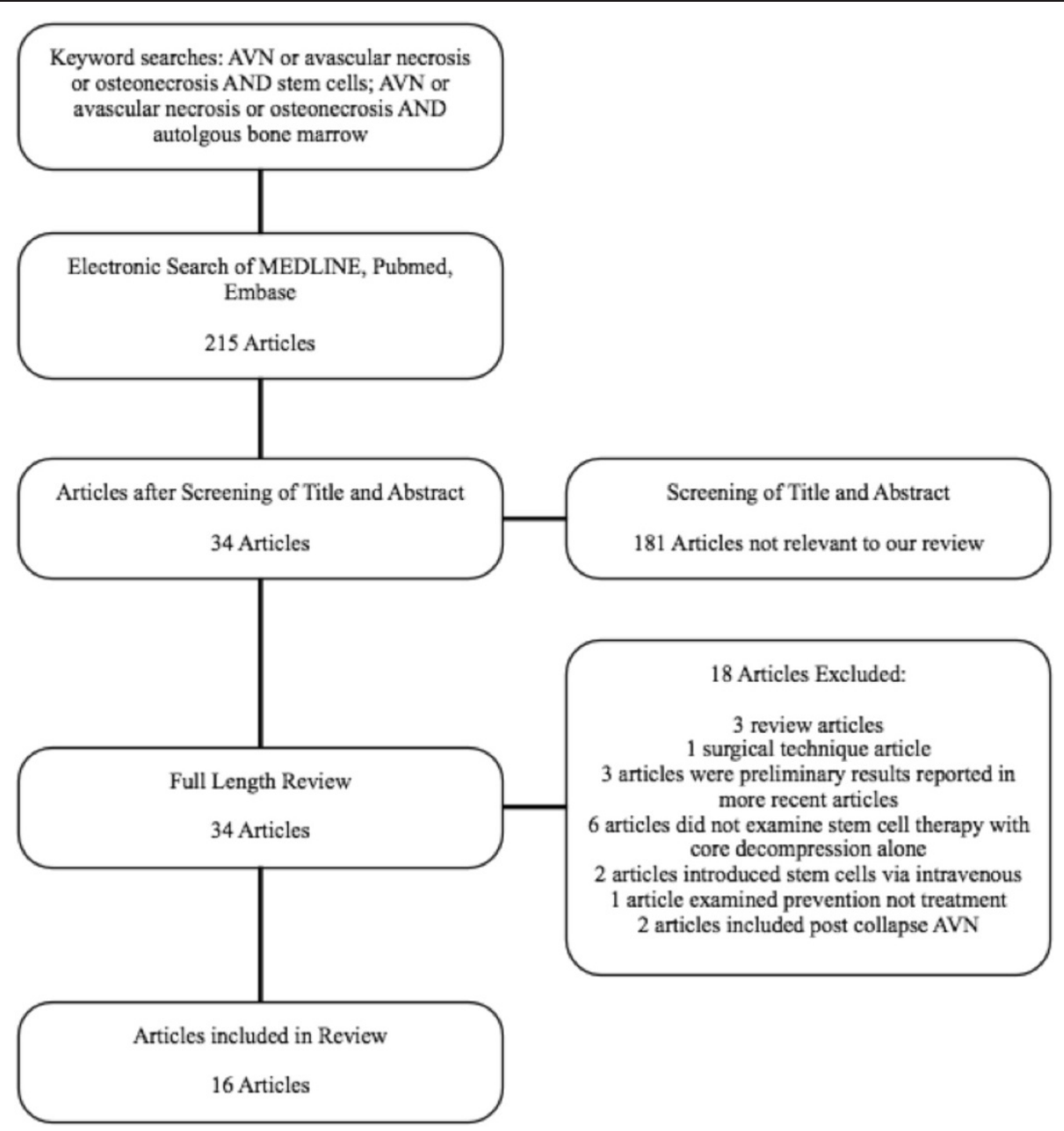

Figure 1 Search, screening and selection of articles for review.

peripheral blood hematopoietic SC (1 study) [17], cultured endothelial progenitor cells (EPC) (1 study) [31], and human immature dental pulp SC (1 study) [4] (Table 1).

\section{Histologic analysis}

All preclinical studies performed a histologic evaluation of the FH's after SC treatment, examining for osteogenesis. In addition, 5 of the studies performed a quantitative histomorphometric analysis for osteogenesis $[6,11,12,31,32]$. Seven studies examined the FH's for neovascularization $[6,11,17,30-32,34]$.

\section{Imaging analysis}

Six of the 11 studies used a variety of imaging techniques to evaluate bone formation $[6,10,11,30,32,34]$. Wen et al. used computed tomography (CT), magnetic resonance imaging (MRI), and CT perfusion imaging to evaluate the effectiveness of autologous cultured bone marrow SC therapy [30]. Abudusaimi et al., Xie et al. and Aimaiti et al. used micro CT scan to evaluate bone volume, bone mineral density and trabecular volume [10,32,34]. Sun et al. used micro CT angiography to evaluate angiogenesis [6]. Hang et al. used single photon emission computed tomography (SPECT) and radiographs to evaluate bone density and FH shape [11].

\section{Preclinical study findings \\ Histology (11 studies)}

Nine studies reported an increase in bone formation in the $\mathrm{SC}$ treatment group compared to $\mathrm{CD}$ alone [4,6,10-12,31-34] and two studies reported an increase in bone formation compared to no treatment $[17,30]$. In the 5 studies that performed a quantitative histomorphometric analysis, all 5 studies reported significantly increased bone formation $(\mathrm{p}<0.05)$ following SC therapy versus $C D$ alone $[6,11,12,31,32]$.

Five studies performing a histologic assessment of neovascularization following $\mathrm{SC}$ treatment found improvement $(\mathrm{p}<0.05)$ in the SC treatment groups compared to $\mathrm{CD}$ alone [6,11,30-32]. One study found higher levels of 
Table 1 Preclinical study characteristics and results

\begin{tabular}{|c|c|c|c|c|c|c|c|c|}
\hline \multirow[t]{3}{*}{ Study } & \multirow[t]{3}{*}{ Animal model } & \multirow[t]{3}{*}{ Stem cell therapy } & \multicolumn{6}{|c|}{ Results } \\
\hline & & & \multicolumn{2}{|c|}{ Histology } & \multicolumn{4}{|c|}{ Imaging } \\
\hline & & & Bone formation & Angiogenesis & X-ray & SPECT & $\mathrm{CT}$ & MR \\
\hline Wen et al. [30] & Rabbit & BMMNC-MSC & +ve & $+v e^{*}$ & - & - & +ve & $+v e$ \\
\hline Sun et al. [6] & Rabbit & BMMNC & $+v e^{*}$ & $+v e^{*}$ & - & - & $+v e^{*}$ & - \\
\hline Yan et al. [12] & Dog & BMMNC-MSC & $+v e^{*}$ & - & - & - & - & - \\
\hline Feitosa et al. [4] & Sheep & hIDPSC, BMMNC-MSC & $+v e$ & - & - & - & - & - \\
\hline Abudusaimi et al. [10] & Rabbit & ADSC & $+v e$ & - & - & - & $+v e^{*}$ & - \\
\hline Aimaiti et al. [34] & Rabbit & ADSC & +ve & +ve & - & - & $+v e^{*}$ & - \\
\hline Song et al. [17] & Rabbit & PBSC & $+\mathrm{ve}$ & $+\mathrm{ve}^{*}$ & - & - & - & - \\
\hline Sun et al. [31] & Rabbit & EPC & $+v e^{*}$ & $+\mathrm{ve}^{*}$ & - & - & - & - \\
\hline Hang et al. [11] & Dog & BMMNC-MSC & $+v e^{*}$ & $+\mathrm{ve}^{*}$ & +ve & +ve & - & - \\
\hline Wen et al. [33] & Rabbit & BMMNC-MSC & $+\mathrm{ve}$ & - & - & - & - & - \\
\hline Xie et al. [32] & Rabbit & cBMMNC & $+v e^{*}$ & $+v e^{*}$ & - & - & $+v e^{*}$ & - \\
\hline
\end{tabular}

BMMNC-MSC = mesenchymal stem cells obtained post bone marrow mononuclear cell culture, hIDPSC = human immature dental pulp stem cells, ADSC = adipose derived stem cells, PBSC = peripheral blood stem cells, EPC = endothelial progenitor cells, $\mathrm{cBMMNC}=\mathrm{cryoperserved} \mathrm{bone} \mathrm{marrow} \mathrm{mononuclear} \mathrm{cells,}$ $+v e=$ positive effect compared to controls, $-v e=$ negative effect compared to controls, $-=$ not measured, ${ }^{*}=$ statistically significant $(p<0.05)$.

neovascularization compared to no treatment [17]. One study did not perform statistical analysis but reported higher levels of neovascularization [34] (Table 1).

\section{Imaging (6 studies)}

On CT imaging, Wen et al. found that the SC group had imaging that closely resembled the normal hip in comparison to $\mathrm{CD}$ alone [30]. On MRI imaging they found decreased FH necrosis volume compared to no treatment, and on CT perfusion imaging they found blood volume to be similar to normal hips (no statistics reported) [30]. Abudusaimi et al., Xie et al. and Aimaiti et al. found significantly higher bone volume, bone mineral density and trabecular volume in the SC group compared to $\mathrm{CD}$ alone $(\mathrm{p}<0.05)$ on micro CT $[10,32,34]$.

Sun et al. performed micro CT angiography and found improved angiogenesis $(\mathrm{p}<0.05)[6]$. Hang et al. found that the $\mathrm{CD}$ only group had decreased uptake of radioactivity on SPECT compared to SC treatment group, indicative of worse perfusion [11]. Radiographs also revealed that the CD only group had worse results, with irregular articular surfaces and heterogenous density of the $\mathrm{FH}$ in comparison to the SC group (no statistics reported) [11] (Table 1).

\section{Clinical study characteristics Study design}

The clinical studies included two randomized control trials (RCT) $[8,14]$, one non randomized comparison study (nRCT) [2], and two case series [9,35]. The length of follow up for the RCTs was 24 months [14], and 60 months [8]. The nRCT had a follow up of 60 months [2]. The case series' examined outcomes at an average follow up of 27.6 months (12-40 months) [9], and 13 years ( $8-18$ years) [35].

\section{Sample size}

Sample size (n) was recorded as number of hips. Combined, the 5 studies comprised 763 hips. Across studies, $\mathrm{n}$ varied from a minimum of 24 [2] to a maximum of 534 [35] (Table 2). None of the studies reported a power calculation.

\section{Avascular necrosis classification and etiology}

Combined, the studies included patients with the following etiologies for AVN: trauma [8,14], steroid use $[2,8,9,14,35]$, ethanol use [2,8,9,14,35], pregnancy [14], Cushing's disease [14], Caisson disease [8], sickle cell disease [34], and idiopathic $[2,8,9,14]$. Hernigou et al. did not specify the cause of AVN for 117 of 534 hips in their case series [35] (Table 2). The severity of AVN was classified using two grading systems across the 5 studies. Four of the studies utilized the Association Research Circulation Osseous (ARCO) classification $[2,8,9,14]$ and included patients with an ARCO classification of 1-2 (precollapse). One study used the Ficat classification, and included patients in Ficat stage 1 or 2 [35] (Table 2).

\section{Stem cell treatment protocol}

Four studies utilized concentrated BMMNC harvested from the iliac crests of each patient as their SC treatment $[2,9,14,35]$. Zhao et al. used cultured autologous BMMNC harvested from the proximal femur of each patient as their SC treatment [8]. After bone marrow was harvested, in vitro expansion of the mesenchymal SC was performed for 2 weeks prior to reimplantation. SC treatment was 
Table 2 Clinical Study Characteristics

\begin{tabular}{|c|c|c|c|c|c|}
\hline Study & Type & $\mathbf{n}$ & Initial AVN class & AVN etiology (\# of hips) & Treatment protocol \\
\hline Hernigou et al. [35] & Case series & 534 & Ficat 1-2 & $\begin{array}{c}\text { steroid (101), ethanol (150), sickle cell (166), } \\
\text { not specified (117) }\end{array}$ & Concentrated BMMNC \\
\hline Wang et al. [9] & Case series & 50 & ARCO 1-2 & steroid (25), ethanol (19), idiopathic (6) & Concentrated BMMNC \\
\hline Gangji et al. [2] & $\mathrm{nRCT}$ & 24 & ARCO 1-2 & steroid (20), ethanol (2), idiopathic (2) & Concentrated BMMNC \\
\hline Sen et al. [14] & RCT & 51 & ARCO 1-2 & $\begin{array}{c}\text { trauma (17), steroid (20), ethanol 8), idiopathic (2), } \\
\text { pregnancy (2), Cushings (2) }\end{array}$ & Concentrated BMMNC \\
\hline Zhao et al. [8] & RCT & 97 & ARCO $1 \mathrm{C}-2 \mathrm{C}$ & $\begin{array}{l}\text { trauma (20), steroid (24), ethanol (19), Caisson (11), } \\
\text { idiopathic (30) (some patients had more than one etiology) }\end{array}$ & Cultured BMMNC \\
\hline
\end{tabular}

BMMNC = bone marrow mononuclear cells, $\mathrm{n}=$ number of hips, ARCO = Association Research Circulation Osseous classification, $\mathrm{nRCT}=$ non randomized control trial, $\mathrm{RCT}=$ randomized control trial.

performed in conjunction with $\mathrm{CD}$ for all clinical studies (Table 2).

\section{Stem cell dose}

SC dose was measured using a variety of methods - total mononucleated cell count (TMNCC), CD34+ cell count, number of fibroblast colony forming units (F-CFU) and total mesenchymal SC count (TMSCC). TMNCC is a measure of all the nucleated cells including mature nucleated cells and mesenchymal SC. CD34+ cells are a marker of hematopoeitic precursor cells and F-CFU are a measure of mesenchymal SC (each F-CFU is thought to arise from clonal expansion of mesenchymal SC). TMSCC is an approximate count of the number of $\mathrm{SC}$ and was used by Zhao et al. prior to reimplantation of cultured mesenchymal SC [8].

TMNCC was measured in 4 studies and ranged from $5 \times 10^{8}$ to $19 \times 10^{8}$ cells $[2,9,14]$. CD34+ cell counts were measured in two studies $\left(1.9 \times 10^{7}\right.$ to $5 \times 10^{7}$ cells $)$ $[2,14]$. F-CFU counts were measured in two studies (mean F-CFU count of $1.76 \times 10^{3}$ to $2.4 \times 10^{3}$ ) [2,35]. TMSCC was reported in one study $\left(2.0 \times 10^{6}\right.$ cells $)$ [8] (Table 3).

\section{Examined outcomes}

Across studies a variety of patient reported outcomes were reported, including Harris Hip Score (HHS) (4 studies) [8,9,14,35], Lequesne index (1 study) [2], Western Ontario and McMaster Osteoarthritis index (WOMAC) (1 study) [2], and pain visual analog score (VAS) (1 study) [2]. Three studies examined progression to more advanced ARCO stage $[2,8,9]$, and 3 studies examined volume of necrotic lesion by MRI $[2,8,35]$. Hip survivorship was measured in all 5 studies and was defined as conversion to THA (4 studies) $[2,9,14,35]$, and conversion to THA or need for vascularized bone grafting (1 study) [8]. Two studies reported KM survival curves as part of their hip survivorship analysis $[2,14]$.

\section{Clinical study results}

Patient reported outcomes (5 studies)

Four of the studies reported HHS $[8,9,14,35]$. Zhao et al. found a statistically significant increase in HHS 60 months following $\mathrm{SC}$ therapy compared to $\mathrm{CD}$ only in patients with ARCO stage $1 \mathrm{C} / 2 \mathrm{~B} / 2 \mathrm{C}(\mathrm{p}<0.05$, raw score not reported), and a trend for ARCO stage $2 \mathrm{~A}(\mathrm{p}=0.06$, raw score not reported) [8]. Sen et al. found a statistically significant difference in HHS for the SC treated patients compared to CD only at 12 months follow up (83.65 \pm 8.04 vs. $76.68 \pm 13.86, \mathrm{p}<0.05$ ) [14]. At 24 months, overall HHS was not significantly improved between the two groups $(82.42 \pm 9.63$ vs. $77.39 \pm 16.98, \mathrm{p}=0.09)$, but the pain and deformity domains of the HHS were still in favor of the SC therapy group ( $<<0.05$, raw score not reported) [14]. Wang et al. reported statistically significant $(\mathrm{p}<0.05)$ improvements in HHS score at an average of 27.6 months post $\mathrm{SC}$ treatment for patients in ARCO stage $1 / 2 \mathrm{~A} / 2 \mathrm{~B} /$ $2 \mathrm{C}$, from $90 \pm 0.06$ to $96 \pm 0.06,78.6 \pm 1.02$ to $92.5 \pm 1.22$, $68.2 \pm 6.16$ to $82.6 \pm 8.23$, and $67.8 \pm 11.2$ to $77.9 \pm 15.15$ respectively [9]. Hernigou et al. reported HHS on patients that had not progressed to having THA (420 of 534 hips) [35]. They reported HHS of 70 preoperatively and 88 post

Table 3 Stem cell dose

\begin{tabular}{|c|c|c|c|c|}
\hline Study & TMNCC & CD34+ cell count & F-CFU & TMSCC \\
\hline Hernigou et al. [35] & - & - & $2.4 \times 104$ & - \\
\hline Wang et al. [9] & $15.5 \times 108$ cells & - & - & - \\
\hline Gangji et al. [2] & $19 \times 108$ cells & $1.9 \times 107$ cells & $1.76 \times 104$ & - \\
\hline Sen et al. [14] & $5 \times 108$ cells & $5 \times 107$ cells & - & - \\
\hline Zhao et al. [8] & - & - & - & $2 \times 106$ cell \\
\hline
\end{tabular}

TMNCC $=$ total mononucleated cell count, F-CFU = fibroblast colony forming units, $\mathrm{TMSCC}=$ total mesenchymal stem cell count. 
SC treatment at an average of 13 years follow up (no $\mathrm{p}$ value reported) [35].

Gangji et al. examined 3 patient reported outcomes: Lequesne index, VAS and WOMAC [2]. The SC treatment group had improved Lequesne index compared to $\mathrm{CD}$ group ( $\mathrm{SC}$ group $=4.8 \pm 1.8, \mathrm{CD}$ group Lequesne index not reported, $\mathrm{p}=0.03$ ), and improved VAS (SC group $=$ $20.8 \pm 7.7, \mathrm{CD}$ group VAS not reported, $\mathrm{p}=0.009$ ). WOMAC scores were not significantly different between the groups (raw scores not reported, $\mathrm{p}=0.091$ ) [2] (Table 4).

\section{Progression of avascular necrosis (3 studies)}

Two of 3 studies found a significant decrease in the proportion of patients progressing to ARCO stage 3 or 4 following $\mathrm{SC}$ treatment compared to $\mathrm{CD}$ only treatment, 60 months post procedure $(\mathrm{p}<0.05)[2,8]$. Zhao et al. reported a decrease from $22.7 \%$ (CD group) to 3.7\% (SC group) [8] and Gangji et al. reported a decrease from $72.7 \%$ (CD group) to $23.1 \%$ (SC group) [2]. Gangji et al. also performed a KM survival analysis with progression to ARCO stage 3 as the end point, and found a significantly longer $(\mathrm{p}<0.05)$ time to progression to ARCO stage 3 in the SC group compared to CD
[52.2 months (43.35 - 60.96, 95\% confidence interval (CI)) vs 26.5 months $(13.2$ - 39.74, 95\% CI)] [2]. In their case series, Wang et al. reported a $22 \%$ rate of progression to higher ARCO stage (for hips in ARCO stage 1 or 2 before SC treatment) at an average follow up of 27 months [9] (Table 4).

\section{Volume of necrotic lesion (3 studies)}

Zhao et al. reported a significant decrease in lesion volume in SC treated hips compared to $\mathrm{CD}$ only treated hips with a pretreatment $\mathrm{ARCO}$ stage of $2 \mathrm{~B}$ and $2 \mathrm{C}(\mathrm{ARCO} 2 \mathrm{~B}=$ $6.5 \%$ vs $13.3 \%$ of $\mathrm{FH}$, ARCO $2 \mathrm{C}=13.8 \%$ vs $29.3 \%$ of $\mathrm{FH}$, $\mathrm{p}<0.05)$ at 60 months post treatment [8]. Gangji et al. reported a significant decrease in lesion volume after SC treatment compared to CD only at 24 months follow up (SC group volume decreased $42 \%$, CD group volume decreased $1 \%, \mathrm{p}<0.05)$, and a trend towards decreased lesion volume at 60 months (SC group volume decreased $42 \%, \mathrm{CD}$ group volume decreased $22 \%, \mathrm{p}=0.06$ ) [2] Hernigou et al. reported on lesion volume in 371 of 534 hips in their case series [35]. They found a decrease in lesion size from $26 \mathrm{~cm}^{3}$ to $12 \mathrm{~cm}^{3}$ at an average of 12 years follow up (no statistical analysis reported) [35] (Table 4).

Table 4 Clinical study results for stem cell therapy

\begin{tabular}{|c|c|c|c|c|c|}
\hline Study & Patient reported ou & atcomes & Progression & Lesion volume & Hip survivorship \\
\hline & Outcome & & & & \\
\hline $\begin{array}{l}\text { Hernigou } \\
\text { et al. [35] }\end{array}$ & HHS (13 years) & $\begin{array}{l}\text { Improved compared to } \\
\text { baseline score ( } 88 \text { vs } 70) \wedge\end{array}$ & & $\begin{array}{l}\text { Decreased lesion volume } \\
\left(12 \mathrm{~cm}^{3} \text { vs } 26 \mathrm{~cm}^{3}\right)^{\wedge}\end{array}$ & $\begin{array}{l}17.6 \% \text { conversion rate to THA } \\
\text { at } 13 \text { years follow up }\end{array}$ \\
\hline $\begin{array}{l}\text { Wang } \\
\text { et al. [9] }\end{array}$ & $\mathrm{HHS}$ & $\begin{array}{l}\text { Improved compared to } \\
\text { baseline score }(83.7 \pm \\
10.34 \text { vs } 71.2 \pm 6.56)^{*}\end{array}$ & $\begin{array}{l}23.7 \% \text { rate of progression } \\
\text { to higher ARCO class }\end{array}$ & & $\begin{array}{l}11.8 \% \text { conversion to THA at } \\
27.6 \text { months }\end{array}$ \\
\hline \multirow[t]{3}{*}{$\begin{array}{l}\text { Gangji } \\
\text { et al. [2] }\end{array}$} & Lequesne index & $\begin{array}{l}\text { Improved compared to } \\
\text { CD (SC group } 4.8 \pm 1.8 \\
\text { CD group NR) }\end{array}$ & $\begin{array}{l}\text { Decreased progression } \\
(23.1 \% \text { vs } 72.7 \%)^{*}\end{array}$ & $\begin{array}{l}\text { Decreased lesion volume at } \\
24 \text { months (SC group volume } \\
\text { decreased } 42 \% \text {, CD group } \\
\text { volume decreased } 1 \%)^{*} \text {, no } \\
\text { improvement at } 60 \text { months } \\
\text { (SC group volume decreased } \\
42 \%, \text { CD group volume } \\
\text { decreased } 22 \%) \#\end{array}$ & $\begin{array}{l}\text { No improvement in hip } \\
\text { survivorship ( } 57.2 \text { months vs } \\
50.2 \text { months) }\end{array}$ \\
\hline & VAS pain & $\begin{array}{l}\text { Improved compared to } \\
\text { CD (SC group } 20.8 \pm 7.7, \\
\text { CD group NR) }\end{array}$ & & & \\
\hline & WOMAC & $\begin{array}{l}\text { No improvement } \\
\text { compared to CD } \\
\text { (raw score NR) }\end{array}$ & & & \\
\hline $\begin{array}{l}\text { Sen } \\
\text { et al. [14] }\end{array}$ & HHS (12 months) & $\begin{array}{l}\text { Improved compared } \\
\text { to CD }(83.65 \pm 8.04 \text { vs } \\
76.68 \pm 13.86)^{*}\end{array}$ & & & $\begin{array}{l}\text { Improved hip survivorship } \\
(51.85 \pm 0.15 \text { weeks vs. } \\
46.62 \pm 2.34 \text { weeks)* }\end{array}$ \\
\hline $\begin{array}{l}\text { Zhao } \\
\text { et al. [8] }\end{array}$ & $\begin{array}{l}\text { HHS ARCO 1C,2B,2C } \\
\text { (60 months) }\end{array}$ & $\begin{array}{l}\text { Improved compared to } \\
\text { CD (raw score NR)* }\end{array}$ & $\begin{array}{l}\text { Decreased progression } \\
(3.8 \% \text { vs. } 22.7 \%)^{*}\end{array}$ & $\begin{array}{l}\text { Decreased lesion volume } \\
\text { in ARCO } 2 \mathrm{~B}(6.5 \% \text { vs } 13.3 \% \\
\text { of FH), and ARCO 2C }(13.8 \% \\
\text { vs } 29.3 \%)^{*}\end{array}$ & $\begin{array}{l}\text { Decreased rate of conversion } \\
\text { to THA/vascularized bone } \\
\text { graft in the SC group } \\
\text { compared to CD ( } 3.7 \% \text { vs. } \\
22.7 \%)^{*}\end{array}$ \\
\hline
\end{tabular}




\section{Hip survivorship (5 studies)}

Four studies examined conversion rate to THA $[2,9,14,35]$. Sen et al. performed KM hip survival analysis and they found the SC treatment group to have significantly longer hip survival compared to $\mathrm{CD}$ alone [51.85 weeks (51.54 - 52.15, 95\% CI) vs 46.72 weeks (42.13 - 51.31, 95\% CI), $\log$ rank test $4.44 \mathrm{p}=0.0351$ ] [14]. Gangji et al's $\mathrm{nRCT}$ found no significant difference in rate of conversion to THA between $\mathrm{SC}$ treatment and $\mathrm{CD}$ alone at 60 months of follow up (SC group: 14.3\%, CD only group: $27.3 \%, \mathrm{p}>0.05)$ [2]. They also performed a KM survival analysis and found no significant difference in time to THA between the two groups [mean time to THA - SC group: 57.2 months (53.48-60.97 95\% CI), CD only group: 50.2 months (40.24-60.13 95\% CI), log rank test $\mathrm{p}=0.42$ ] [2]. Hernigou et al. found a $17.6 \%$ conversion rate in their series over an average follow up of 13 years [35], and Wang et al. found a conversion rate of $12 \%$ over an average follow up of 27 months [9].

Zhao et al. found a significant decrease in rate of conversion to THA or need for vascularized bone grafting in the SC group compared to CD alone (3.7\% vs. $22.7 \%$, $\mathrm{p}<0.05)$ [8] (Table 4).

\section{Discussion}

This review systematically examined the current literature on SC therapy for the treatment of early stage (precollapse) AVN of the $\mathrm{FH}$ including clinical and preclinical studies. Preclinical studies yielded encouraging results for treatment of AVN of the FH with SC. Although the source of SC varied among studies, SC treatment of AVN uniformly demonstrated improvements in osteogenesis and vascularization. All 11 studies showed positive effects with respect to bone formation in groups treated with SC. Furthermore, reported X-ray, SPECT, CT and MR outcomes from all studies favoured the SC treatment group. Bone marrow was the most common source of SC but other sources such as adipose and dental pulp were identified. $\mathrm{SC}$ isolated from dental pulp represents a relatively new treatment option with noteworthy potential for use in orthopaedics [4]. Adipose derived SC are another potential alternative to SC from bone marrow. Advantages of adipose derived SC include abundance, ease of isolation, rapid expansion, and multipotency [10].

Despite positive results, relevance of animal models described in preclinical studies should be considered. Corticosteroid and liquid nitrogen induced AVN of the $\mathrm{FH}$ are widely recognized means for induction of AVN in numerous animal models; both lead to ischemic conditions within the FM and eventual osseous infarction producing changes phenotypically similar and clinically relevant to human disease [36]. Some studies, however, have addressed the significance of larger animal models, particularly with respect to translational medicine, as they may better replicate conditions in human AVN. An ovine model of AVN of the FH may better reflect articulation in early-stage human AVN as compared to other disease models [4]. For liquid nitrogen induced disease, the bone defect produced, which is non-negligible in animals with small diameter FHs, has been proposed as a limitation due to its absence from human pathology. This has led some researchers to reject use of this method on rabbits [37].

Results of clinical studies were also encouraging. In our review, the clinical studies used $\mathrm{CD}$ as a means for implanting SC directly into the necrotic region of the $\mathrm{FH}$, in the form of a cell suspension. CD works by decreasing intra-osseous pressure and improving circulation and vascularization [9]. Used alone, however, CD exhibits inconsistent outcomes including poor lesion reconstruction, ultimately leading to $\mathrm{FH}$ collapse $[9,14]$. The progression of AVN of the $\mathrm{FH}$ occurs in consequence of a limited capacity for articular tissue self-repair $[3,11,14]$, including decreased osteogenesis $[11,14]$ and vascularization [3]. This may occur as a result of inadequate numbers of progenitor cells in the proximal femur of patients with AVN of the FH [38]. It is thought that SC implanted into the necrotic region of the $\mathrm{FH}$ work to repopulate the low numbers of progenitor cells [20]. Pluripotent, mesenchymal SC differentiate into various cell types, namely osteoblasts, thereby improving repair mechanisms and potentially reversing damage to bone $[11,12,14]$. In addition to directly increasing bone formation by differentiating into osteoblasts, it is hypothesized that mesenchymal SC have an indirect effect by the expression of cytokines which influence osteogenesis and neovascularization [39,40]. In general, clinical studies reported improvements in patient reported outcomes for those treated with SC; notably, the HHS. Similarly, studies that examined progression to more advanced disease, and lesion volume reported improvements for the SC treatment group. Participants treated with SC did not experience consistent improvements in hip survivorship across studies. None of the studies using a comparative group found worse outcomes for SC treatment.

Considerable variations and inconsistent reporting among clinical studies were observed regarding the dose of SC, etiology of AVN, lesion size, and severity/classification of disease making comparisons between studies challenging. However, there are currently limited numbers of clinical studies addressing SC therapy for treatment of AVN of the $\mathrm{FH}$, and even fewer addressing early-stage disease and administration of SC by $\mathrm{CD}$. Accordingly, we were unable to perform meta-analysis on study results. Quantitative assessment will be a prerequisite to making definitive conclusions on vital therapyrelated factors such as $\mathrm{SC}$ dose and quality. 
Standardization of SC dose has proven difficult due to a lack of uniformly accepted, reliable cell markers which can be used to identify mesenchymal SC [39]. However, the dose of SC used has been reported to impact disease outcome [7]. Both SC dose and quality are also known to affect their clinical potential. Density of SC transplanted to the necrotic $\mathrm{FH}$ was shown to affect the rate of osteogenesis, and thereby bone repair [12]. Quality of transplanted cells affects their proliferative capacity [41]. Prior to routine use of combined SC/CD therapy, defined standards of SC dose and quality, such as CD34+ or CFU counts [42], will likely have to be set in order to accurately evaluate the effect of each therapy. However, as a result of presently observed inconsistencies, and a paucity of studies in this area, further research, examining both SC dose and quality will be prerequisite to routine clinical use of this therapy.

Though not specifically addressed by studies assessed in this review, the impact on treatment outcome of whether cells were derived from a concentrate or a culture may also represent an area for future research. Pre-clinical and clinical studies included examples of both concentrated and cultured cells. Concentrated cells contain all cells and cell types present in the tissue from which they have been derived, not only SC. Concentrated BMMNC from bone marrow aspirate contain hematopoietic progenitor cells, lymphocytes, leucocytes, in addition to nonhematopoietic cells including MSC, EPC, embryonic-like $\mathrm{SC}$ expressing pluripotent markers, and other multipotent or committed cells [43]. Cultured cells, conversely, represent an isolated pool of SC. The comparative regenerative capacity of concentrated vs. cultured cells remains unclear. Despite positive results observed for both treatments within this review, other studies explicitly assessing differences between the two have displayed mixed findings. Use of pure, cultured MSC led to greater improvements in ischemic limb diseases, compared to concentrated BMMNC, in both human and rat models $[44,45]$. Alternatively, BMMNC use displayed beneficial outcomes in treatment of spinal cord injury when compared to MSC [46]. Cost and feasibility must also be considered when selecting an appropriate treatment. Indeed, cultured cells require greater preparation times and are associated with increased cost $[44,47]$. Ultimately, the outcomes of concentrated vs. cultured cells should be assessed for the specific treatment of AVN of the FH in order to develop future robust clinical guidelines for cellular intervention in this disease.

Etiologic risk factors of AVN are also known to significantly affect treatment outcomes [2]. It has been demonstrated that the capacity for SC to differentiate into the necessary osteogenic cells for bone repair and remodeling is limited in patients with alcohol and steroid induced AVN of the FH due to differences in the ischemic environment $[12,48]$. The size of the osteonecrotic lesion is also known to affect overall patient outcome no matter the method of treatment used $[8,49]$. Future studies should aim to use the same AVN classification system as well as account for AVN etiology and lesion size as potential confounding variables.

Several other reviews $[18,38,50-53]$ have been published discussing the use of SC for the treatment of AVN of the femoral head. However to our knowledge, ours is the first systematic review that includes data from several recently published clinical trials $[2,8,14]$. Our review included data from over 700 hips, more than previously published reviews. Additionally, our review included both clinical and pre-clinical studies, furthering the breadth of our review. A limitation of any systematic review is in the quality of the papers available for review. Clinical studies included in our review did not provide sample size and power calculations. Preclinical studies did not always use a classification system to identify stage of AVN of the FH. There were a limited number of comparative trials, and only two RCTs. We included all types of clinical studies, potentially introducing confounding and selection bias. We felt that inclusion of these studies would provide a more comprehensive review of the literature surrounding this topic. Furthermore, meta-analysis was not performed due to the limited number of comparative trials and variable methodology employed in the studies.

\section{Conclusions}

AVN of the FH primarily affects younger, working age individuals and thus leads to increased morbidity and functional disability in this population $[13,30]$. Treatments aimed at halting or delaying progression of disease would provide a welcome alternative to those faced with progression to joint collapse and hip replacement surgery. Combining $\mathrm{CD}$, the most widely used treatment for AVN of the FH to date [30], with SC, could result in a novel long lasting hip preserving treatment option. Pre-clinical studies have demonstrated the potential of $\mathrm{SC}$ for reversing the debilitating damage to the femoral head associated with AVN in vitro. Current clinical studies have suggested beneficial effects on patient reported outcomes, but definitive conclusions regarding hip survival and disease progression cannot be made. Further, more refined clinical studies are needed to establish the effectiveness of SC treatment in AVN of the FH. Quantitative studies including meta-analyses aimed at addressing SC dose and quality standards will be necessary to make fundamental treatment-related deductions. The effects of concentration and culture based preparatory methods for SC therapy should be compared in the context of treating AVN of the FH in order to establish suitable protocols. Demonstrated improvement in hip survivorship is prerequisite to the future of this treatment. 


\section{Abbreviations}

AVN: Avascular necrosis; FH: Femoral head; SC: Stem cells; THA: Total hip arthroplasty; CD: Core decompression; HHS: Harris Hip Score; CT: Computed tomography; MRI: Magnetic resonance imaging; SPECT: Single photon emission computed tomography; RCT: Randomized controlled trial; nRCT: Nonrandomized controlled trial; ARCO: Association Research Circulation Osseous classification; TMNCC: Total mononucleated cell count; TMSCC: Total mesenchymal stem cell count; WOMAC: Western Ontario and McMaster Universities Osteoarthritis index; VAS: Visual analogue scale pain score; BMMNC-MSC: mesenchymal stem cells obtained post BMMNC culture; hIDPSC: Human immature dental pulp stem cells; ADSC: Adipose derived stem cells; PBSC: Peripheral blood stem cells; EPC: Endothelial progenitor cells; cBMMNC: Cryoperserved bone marrow derived mononuclear cells; F-CFU: Fibroblast colony forming units.

\section{Competing interests}

There are no competing interests for any author of this study.

\section{Authors' contributions}

RL contributed to the design of the study, performed collection and assembly of data, analysis and interpretation of data and drafting and critical revision of the article. RG conceived and designed the study, drafted and critically revised the article, and gave final approval of the article. HE performed data collection and assembly and drafting of the article. SM performed data collection and assembly and drafting of the article. NM participated in study design and coordination, revised and gave final approval of the article. All authors read and approved the final manuscript.

\section{Role of the funding source}

No external funding was provided for the purposes of this study.

\section{Author details}

${ }^{1}$ Nickle 3, Kingston General Hospital, 76 Stuart Street, Kingston, ON K7L 2 V7, Canada. ${ }^{2}$ Division of Orthopaedic Surgery, Toronto Western Hospital, 399 Bathurst Street EW 1-427, Toronto, Ontario M5T 2S8, Canada.

\section{Received: 8 January 2014 Accepted: 7 May 2014}

Published: 16 May 2014

\section{References}

1. Yoshioka T, Mishima H, Akaogi H, Sakai S, Li M, Ochiai N: Concentrated autologous bone marrow aspirate transplantation treatment for corticosteroid-induced osteonecrosis of the femoral head in systemic lupus erythematosus. Int Orthop 2011, 35:823-829. doi:10.1007/s00264-010-1048-y.

2. Gangji V, De Maertelaer V, Hauzeur J-P: Autologous bone marrow cell implantation in the treatment of non-traumatic osteonecrosis of the femoral head: Five year follow-up of a prospective controlled study. Bone 2011, 49:1005-1009. doi:10.1016/j.bone.2011.07.032.

3. Lee H-S, Huang G-T, Chiang H, Chiou L-L, Chen M-H, Hsieh C-H, Jiang C-C: Multipotential mesenchymal stem cells from femoral bone marrow near the site of osteonecrosis. Stem Cells 2003, 21:190-199. doi:10.1634/ stemcells.21-2-190

4. Feitosa M-L-T, Fadel L, Beltrão-Braga P-C-B, Wenceslau C-V, Kerkis I, Kerkis A, Birgel Júnior E-H, Martins J-F, Martins Ddos S, Miglino M-A, Ambrósio C-E: Successful transplant of mesenchymal stem cells in induced osteonecrosis of the ovine femoral head: preliminary results. Acta Cir Bras 2010, 25:416-422.

5. Matsuya H, Kushida T, Asada T, Umeda M, Wada T, lida H: Regenerative effects of transplanting autologous mesenchymal stem cells on corticosteroid-induced osteonecrosis in rabbits. Mod Rheumatol 2008, 18:132-139. doi:10.1007/s10165-008-0023-6.

6. Sun $Y$, Feng $Y$, Zhang $C$ : The effect of bone marrow mononuclear cells on vascularization and bone regeneration in steroid-induced osteonecrosis of the femoral head. Joint Bone Spine 2009, 76:685-690. doi:10.1016/j. jbspin.2009.04.002.

7. Hernigou P, Beaujean F: Treatment of osteonecrosis with autologous bone marrow grafting. Clin Orthop Relat Res 2002, 405:14-23.

8. Zhao D, Cui D, Wang B, Tian F, Guo L, Yang L, Liu B, Yu X: Treatment of early stage osteonecrosis of the femoral head with autologous implantation of bone marrow-derived and cultured mesenchymal stem cells. Bone 2012, 50:325-330. doi:10.1016/j.bone.2011.11.002.

9. Wang B-L, Sun W, Shi Z-C, Zhang N-F, Yue D-B, Guo W-S, Xu S-Q, Lou J-N, Li $Z-R:$ Treatment of nontraumatic osteonecrosis of the femoral head with the implantation of core decompression and concentrated autologous bone marrow containing mononuclear cells. Arch Orthop Trauma Surg 2010, 130:859-865. doi:10.1007/500402-009-0939-0.

10. Abudusaimi A, Aihemaitijiang Y, Wang Y-H, Cui L, Maimaitiming S, Abulikemu M: Adipose-derived stem cells enhance bone regeneration in vascular necrosis of the femoral head in the rabbit. J Int Med Res 2011, 39:1852-1860

11. Hang D, Wang Q, Guo C, Chen Z, Yan Z: Treatment of Osteonecrosis of the Femoral Head with VEGF (165) Transgenic Bone Marrow Mesenchymal Stem Cells in Mongrel Dogs. Cells Tissues Organs 2012, 195(6):495-506. doi:10.1159/000329502.

12. Yan Z, Hang D, Guo C, Chen Z: Fate of mesenchymal stem cells transplanted to osteonecrosis of femoral head. J Orthop Res 2009, 27:442-446. doi:10.1002/ jor.20759.

13. Li Z-H, Liao W, Cui X-L, Zhao Q, Liu M, Chen Y-H, Liu T-S, Liu N-L, Wang F, Yi $Y$, Shao N-S: Intravenous transplantation of allogeneic bone marrow mesenchymal stem cells and its directional migration to the necrotic femoral head. Int J Med Sci 2011, 8:74-83.

14. Sen R-K, Tripathy S-K, Aggarwal S, Marwaha N, Sharma R-R, Khandelwal N: Early results of core decompression and autologous bone marrow mononuclear cells instillation in femoral head osteonecrosis: a randomized control study. J Arthroplasty 2012, 27:679-686. doi:10.1016/j. arth.2011.08.008

15. Yan Z-Q, Chen Y-S, Li W-J, Yang Y, Huo J-Z, Chen Z-R, Shi J-H, Ge J-B: Treatment of osteonecrosis of the femoral head by percutaneous decompression and autologous bone marrow mononuclear cell infusion. Chin J Traumatol 2006, 9:3-7.

16. Gangji V, Hauzeur J-P, Matos C, De Maertelaer V, Toungouz M, Lambermont $\mathrm{M}$ : Treatment of osteonecrosis of the femoral head with implantation of autologous bone-marrow cells. A pilot study. J Bone Joint Surg Am 2004, 86-A:1153-1160.

17. Song H-J, Lan B-S, Cheng B, Zhang K-F, Yan H-W, Wang W-Z, Gao Z-O: Treatment of early avascular necrosis of femoral head by small intestinal submucosal matrix with peripheral blood stem cells. Transplant Proc 2011, 43:2027-2032. doi:10.1016/j.transproceed.2010.12.060.

18. Gangji V, Hauzeur J-P: Cellular-based therapy for osteonecrosis. Orthop Clin North Am 2009, 40:213-221. doi:10.1016/j.ocl.2008.10.009.

19. Gangji V, Toungouz M, Hauzeur J-P: Stem cell therapy for osteonecrosis of the femoral head. Expert Opin Biol Ther 2005, 5:437-442. doi:10.1517/ 14712598.5.4.437.

20. Hernigou P, Poignard A, Manicom O, Mathieu G, Rouard H: The use of percutaneous autologous bone marrow transplantation in nonunion and avascular necrosis of bone. J Bone Joint Surg (Br) 2005, 87:896-902. doi:10.1302/0301-620X.87B7.16289.

21. Gangji V, Hauzeur J-P: Treatment of osteonecrosis of the femoral head with implantation of autologous bone-marrow cells. Surgical technique. J Bone Joint Surg Am 2005, 87(Suppl 1):106-112. doi:10.2106/JBJS.D.02662.

22. Hernigou P, Daltro G, Filippini P, Mukasa M-M, Manicom O: Percutaneous implantation of autologous bone marrow osteoprogenitor cells as treatment of bone avascular necrosis related to sickle cell disease. Open Orthop J 2008, 2:62-65. doi:10.2174/1874325000802010062.

23. Kawate K, Yajima H, Ohgushi H, Kotobuki N, Sugimoto K, Ohmura T, Kobata Y, Shigematsu K, Kawamura K, Tamai K, Takakura Y: Tissue-engineered approach for the treatment of steroid-induced osteonecrosis of the femoral head: transplantation of autologous mesenchymal stem cells cultured with beta-tricalcium phosphate ceramics and free vascularized fibula. Artif Organs 2006, 30:960-962. doi:10.1111/j.1525-1594.2006.00333.x.

24. Pak J: Autologous adipose tissue-derived stem cells induce persistent bonelike tissue in osteonecrotic femoral heads. Pain Physician 2012, 15:75-85.

25. Peng J, Wen C, Wang A, Wang Y, Xu W, Zhao B, Zhang L, Lu S, Qin L, Guo Q, Dong L, Tian J: Micro-CT-based bone ceramic scaffolding and its performance after seeding with mesenchymal stem cells for repair of load-bearing bone defect in canine femoral head. J Biomed Mater Res Part B Appl Biomater 2011, 96:316-325. doi:10.1002/jbm.b.31770.

26. Xiao Z-M, Jiang H, Zhan X-L, Wu Z-G, Zhang X-L: Treatment of osteonecrosis of femoral head with BMSCs-seeded bio-derived bone materials combined with rhBMP-2 in rabbits. Chin J Traumatol 2008, 11:165-170. 
27. Xu M, Peng D: Mesenchymal stem cells cultured on tantalum used in early-stage avascular necrosis of the femoral head. Med Hypotheses 2011, 76:199-200. doi:10.1016/j.mehy.2010.09.028.

28. Yamasaki T, Yasunaga Y, Ishikawa M, Hamaki T, Ochi M: Bone-marrowderived mononuclear cells with a porous hydroxyapatite scaffold for the treatment of osteonecrosis of the femoral head: a preliminary study. J Bone Joint Surg (Br) 2010, 92:337-341. doi:10.1302/0301-620X.92B3.22483.

29. Song H-J: Peripheral Blood Stem Cell Transplantation for Ischemic Femoral Head Necrosis. Transplant Proc 2010, 42(7):2824. doi: 10.1016/j. transproceed.2010.02.077.

30. Wen Q, Ma L, Chen Y-P, Yang L, Luo W, Wang X-N: Treatment of avascular necrosis of the femoral head by hepatocyte growth factor-transgenic bone marrow stromal stem cells. Gene Ther 2008, 15:1523-1535. doi:10.1038/gt.2008.110.

31. Sun Y, Feng Y, Zhang C, Cheng $X$, Chen $S, A i$ Z, Zeng B: Beneficial effect of autologous transplantation of endothelial progenitor cells on steroidinduced femoral head osteonecrosis in rabbits. Cell Transplant 2011, 20:233-243. doi:10.3727/096368910X522234.

32. Xie X-H, Wang X-L, He Y-X, Liu Z, Sheng H, Zhang G, Qin L: Promotion of bone repair by implantation of cryopreserved bone marrow-derived mononuclear cells in a rabbit model of steroid-associated osteonecrosis. Arthritis Rheum 2012, 64:1562-1571. doi:10.1002/art.34525.

33. Wen $Q$, Jin D, Zhou C-Y, Zhou M-Q, Luo W, Ma L: HGF-transgenic MSCs can improve the effects of tissue self-repair in a rabbit model of traumatic osteonecrosis of the femoral head. PLoS One 2012, 7:e37503. doi:10.1371/journal.pone.0037503.

34. Aimaiti A, Saiwulaiti Y, Saiyiti M, Wang Y-H, Cui L, Yusufu A: Therapeutic effect of osteogenically induced adipose derived stem cells on vascular deprivation-induced osteonecrosis of the femoral head in rabbits. Chin J Traumatol 2011, 14:215-220.

35. Hernigou P, Poignard A, Zilber S, Rouard H: Cell therapy of hip osteonecrosis with autologous bone marrow grafting. Indian J Orthop 2009, 43:40-45. doi:10.4103/0019-5413.45322.

36. Hernigou P, Beaujean F, Lambotte J-C: Decrease in the mesenchymal stem-cell pool in the proximal femur in corticosteroid-induced osteonecrosis. J Bone Joint Surg (Br) 1999, 81:349-355.

37. Jones $E$, Yang $X$ : Mesenchymal stem cells and bone regeneration: current status. Injury 2011, 42:562-568. doi:10.1016/j.injury.2011.03.030.

38. Rackwitz L, Eden L, Reppenhagen S, Reichert JC, Jakob F, Walles H, Pullig O, Tuan R-S, Rudert M, Nöth U: Stem cell- and growth factor-based regenerative therapies for avascular necrosis of the femoral head. Stem Cell Res Ther 2012, 3:7. doi:10.1186/scrt98.

39. Suh K-T, Kim S-W, Roh H-L, Youn M-S, Jung J-S: Decreased osteogenic differentiation of mesenchymal stem cells in alcohol-induced osteonecrosis. Clin Orthop Relat Res 2005, 431:220-225.

40. Mont M-A, Jones L-C, Hungerford D-S: Nontraumatic osteonecrosis of the femoral head: ten years later. J Bone Joint Surg Am 2006, 88:1117-1132. doi:10.2106/JBJS.E.01041.

41. Jones L-C, Hungerford D-S: Osteonecrosis: etiology, diagnosis, and treatment. Curr Opin Rheumatol 2004, 16:4343-4449.

42. Hauzeur J-P, Gangji V: Phases 1-3 clinical trials using adult stem cells in osteonecrosis and nonunion fractures. Stem Cells Int 2010, 2010:410170. doi: $10.4061 / 2010 / 410170$

43. Cuende N, Rico L, Herrera C: Concise Review: Bone Marrow Mononuclear Cells for the Treatment of Ischemic Syndromes: Medicinal Product or Cell Transplantation? Stem Cells Trans Med 2012, 1(5):403-408.

44. Iwase T, Nagaya N, Fujii T, Itoh T, Murakami S, Matsumoto T, Kangawa K, Kitamura S: Comparison of Angiogenic Potency Between Mesenchymal Stem Cells and Mononuclear Cells in a Rat Model of Hindlimb Ischemia. Cardiovasc Res 2005, 66:543-551.

45. Lu D, Chen B, Liang Z, Deng W, Jiang Y, Li S, Xu J, Wu Q, Zhang Z, Xie B, Chen S: Comparison of Bone Marrow Mesenchymal Stem Cells with Bone Marrow-Derived Mononuclear Cells for Treatment of Diabetic Critical Limb Ischemia and Foot Ulcer: A Double-Blind, Randomized Controlled Trial. Diabetes Res Clin Pract 2011, 92(1):26-36.

46. Samdani A-F, Paul C, Betz R-R, Fischer I, Neuhuber B: Transplantation of Human Marrow Stromal Cells and Mono-Nuclear Bone Marrow Cells into the Injured Spinal Cord: A Comparative Study. Spine (Phila Pa 1976) 2009, 34(24):2605-2612.
47. Ikebe C, Suzuki K: Mesenchymal Stem Cells for Regenerative Therapy: Optimization of Cell Preparation Protocols. Biomed Res Int 2014, 2014:951512.

48. Jones K-B, Seshadri T, Krantz R, Keating A, Ferguson P-C: Cell-based therapies for osteonecrosis of the femoral head. Biol Blood Marrow Transplant 2008, 14:1081-1087. doi:10.1016/j.bbmt.2008.06.017.

49. Sen R-K: Management of avascular necrosis of femoral head at precollapse stage. Indian J Orthop 2009, 43:6-16. doi:10.4103/0019-5413.45318.

50. Schallmoser K, Bartmann C, Wagner W: Replicative Senescence-Assosiated Gene Expression Changes in Mesenchymal Stromal Cells are Similar under Different Culture Conditions. Haematologica 2010, 95(6):867-874.

51. Pamphilon D, Mijovic A: Storage of Hemopoietic Stem Cells. Asian J Transfus Sci 2007, 1(2):71-76.

52. Boss J-H, Misselvich I: Osteonecrosis of the Femoral Head of Laboratory Animals: The Lessons Learned from a Comparative Study of Osteonecrosis in Man and Experimental Animals. Vet Pathol 2003, 40(4):345-354.

53. Wang C, Wang J, Zhang Y, Yuan C, Liu D, Pei Y, Li X, Wu Z, Li Y, Guo Z: A Canine Model of Femoral Head Osteonecrosis Induced by an Ethanol Injection Navigated by a Novel Template. Int J Med Sci 2013, 10(11):1451-1458

\section{doi:10.1186/1471-2474-15-156}

Cite this article as: Lau et al:: Stem cell therapy for the treatment of early stage avascular necrosis of the femoral head: a systematic review. BMC Musculoskeletal Disorders 2014 15:156

\section{Submit your next manuscript to BioMed Central and take full advantage of:}

- Convenient online submission

- Thorough peer review

- No space constraints or color figure charges

- Immediate publication on acceptance

- Inclusion in PubMed, CAS, Scopus and Google Scholar

- Research which is freely available for redistribution

Submit your manuscript at www.biomedcentral.com/submit
C Biomed Central 